\title{
Characterization of pathogenicity island prophage in clinical and environmental strains of Vibrio cholerae
}

\begin{abstract}
Correspondence
M. R. Pourshafie

pour@pasteur.ac.ir

A. Rastegar Lari

azizlari@gmail.com
\end{abstract}

Received 1 March 2011

Accepted 15 August 2011

\author{
H. Mohammadi-Barzelighi, ${ }^{1}$ B. Bakhshi, ${ }^{2}$ A. Rastegar Lari $^{3}$ \\ and M. R. Pourshafie ${ }^{4}$ \\ ${ }^{1}$ Department of Microbiology, Tehran University of Medical Sciences, Tehran, Iran \\ ${ }^{2}$ Department of Bacteriology, Tarbiat Modares University, Tehran, Iran \\ ${ }^{3}$ Antimicrobial Resistance Research Center, Tehran University of Medical Sciences, Tehran, Iran \\ ${ }^{4}$ Department of Bacteriology, Pasteur Institute of Iran, Tehran, Iran
}

\section{INTRODUCTION}

Vibrio cholerae $\mathrm{O} 1$ causes acute gastrointestinal disease, which is reported annually in Iran with differing frequency (Bakhshi et al., 2008). However, non-O1/non-O139 strains are not associated with epidemics, but several cases of sporadic diarrhoea, gastroenteritis and skin infections have been reported (Restrepo et al., 2006; Rozemeijer et al., 2009).

The vibrio pathogenicity island (VPI) is a primary genetic factor required for the emergence of epidemic $V$. cholerae. The VPI has several features such as a low mol\% $\mathrm{G}+\mathrm{C}$ content (35 mol\%), phage-like attachment (att) sites at its termini, insertion at the ssr $A$ site, a phage-like integrase gene (int) and a transposase-like gene (vpiT) (Heidelberg et al., 2000). ToxT is a soluble transcriptional activator that amplifies its own expression, directly regulates the expression of cholera toxin (CT) encoded by integrated CTX phage (DiRita et al., 1991) and five other genes, aldA, $\operatorname{tag} A, \operatorname{acf} A$, acfD and $t c p I$, in the VPI cluster (Peterson \& Mekalanos, 1988). Other virulence factors such as toxin co-regulated pilus (TCP), encoded by phage, mediate the intestinal colonization (Kirn et al., 2000). TcpP and TcpH have been shown to regulate CT and TCP expression possibly through ToxT (Carroll et al., 1997; Häse \& Mekalanos, 1998). The majority

Abbreviations: CT, cholera toxin; L-PCR, long template PCR; TCP, toxin co-regulated pilus; VPI, vibrio pathogenicity island. of $V$. cholerae serotypes do not contain genes for CT and TCP (Taylor et al., 1988; Bakhshi et al., 2009), whereas the gene for ToxR is ubiquitously present (Nandi et al., 2000).

Other proteins within the VPI segment are AldA and TagA, which encode aldehyde dehydrogenase and metalloprotease activities, respectively (Parsot \& Mekalanos, 1991; Szabady et al., 2011). ACF (accessory colonization factor), which is located in the right segment of the VPI, controls the expression of $\mathrm{CT}$ and $\mathrm{AcfB}$, playing a role in chemotaxis, thereby assisting in intestinal colonization (Hughes et al., 1995).

In the present study, we compared the entire VPI loci of clinical and environmental $V$. cholerae isolates to address the following questions: (i) whether all clinical $V$. cholerae strains possessed an identical VPI gene content; (ii) the difference between the VPI gene content of the environmental and clinical isolates; and (iii) the correlation between VPI gene content and the bacterial attachment pattern.

\section{METHODS}

Bacterial strains. A total of $86 \mathrm{~V}$. cholerae isolates were included in this study. The 46 environmental $V$. cholerae isolates were obtained from surface water, and were biochemically identified and confirmed using intergenic 16srRNA-23srRNA specific primers (Choopun et al., 


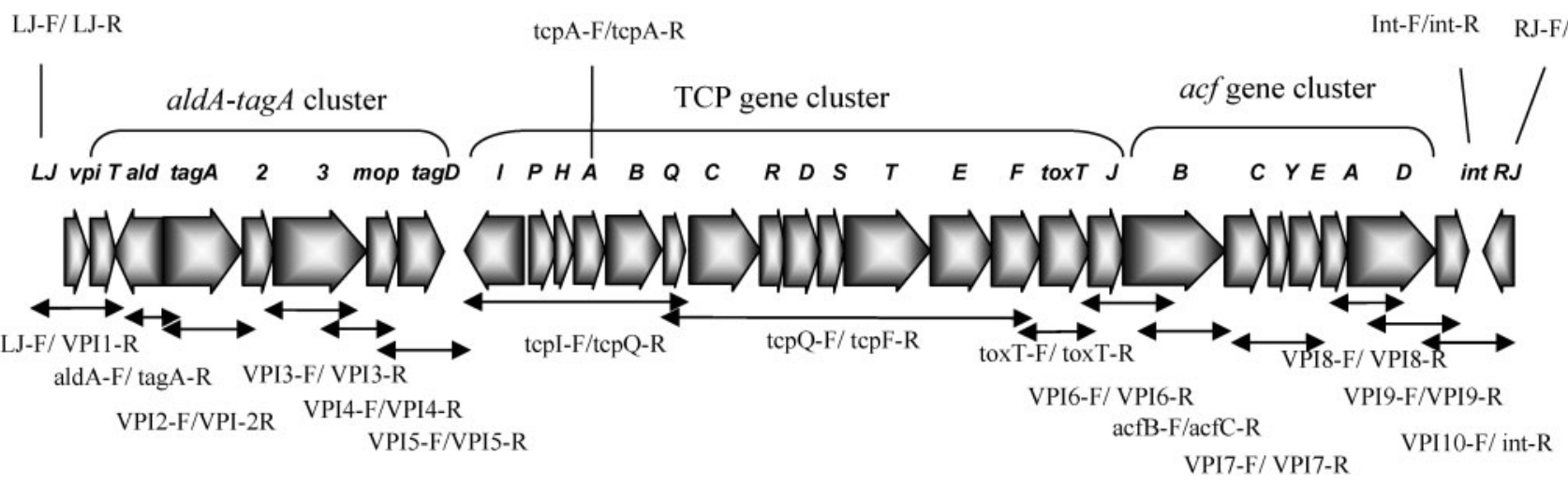

Fig. 1. Schematic presentation of VPI (39.5 kb) in V. cholerae El Tor strain N16961. The ORFs and gene clusters are shown. Black arrowheads indicate the location of the PCR primers listed in Table 1.

2002). The 40 clinical isolates were randomly selected from our $V$. cholerae culture collection, and were obtained from patients in different provinces in Iran during the years 2004-2006. V. cholerae ATCC 14035 was used as a positive control throughout the experiments.

PCR, long template PCR (L-PCR) and RFLP analysis. Fig. 1 shows the general structure of the VPI cluster gene content. Classical PCR was used for the analysis of aldA-tagA and acf gene clusters. DNA was extracted using a QIAamp DNA mini kit (Qiagen) and PCR was performed in a reaction mixture with total volume of $25.5 \mu \mathrm{l}$, containing $5 \mu \mathrm{l}$ template DNA $(20 \mathrm{ng}), 2.5 \mu \mathrm{l} 10 \times$ Taq polymerase buffer [100 mM Tris/HCl ( $\mathrm{pH} 8.3$ ), $500 \mathrm{mM} \mathrm{KCl}$ and $15 \mathrm{mM} \mathrm{MgCl}_{2}$ ], $0.25 \mu \mathrm{l}\left(100 \mathrm{pmol}_{\mu \mathrm{l}}^{-1}\right)$ each primer, $0.25 \mu \mathrm{l}(10 \mathrm{mM}) \mathrm{dNTPs}, 0.2 \mu \mathrm{l}$ $\left(5 \mathrm{U}^{-1}\right.$ ) Taq DNA polymerase and $16.8 \mu \mathrm{l}$ sterilized distilled water.

PCR was carried out as follows: initial denaturation step at $94{ }^{\circ} \mathrm{C}$ for $5 \mathrm{~min}$; followed by 30 cycles consisting of denaturation $\left(94{ }^{\circ} \mathrm{C}\right.$ for $1 \mathrm{~min}$ ), annealing $\left(58{ }^{\circ} \mathrm{C}\right.$ for $1 \mathrm{~min}$, separately adjusted for each set of primer pairs) and extension $\left(72{ }^{\circ} \mathrm{C}\right.$ for $\left.1 \mathrm{~min}\right)$; followed by a final extension step at $72{ }^{\circ} \mathrm{C}$ for $3 \mathrm{~min}$.

The Expand L-PCR system (Roche Diagnostic) and two set of primers, tcpI-F/tcpQ-R and tcpQ-F/tcpF-R (targeting between the $t c p I$ through $t c p F$ ) were used (Fig. 1). L-PCR was carried out in a volume of $25 \mu \mathrm{l}$, with $2.5 \mu \mathrm{l}$ each primer $(300 \mathrm{nM}), 2 \mu \mathrm{l}$ dNTP $(350 \mu \mathrm{M}), 2.5 \mu \mathrm{l} 10 \times \mathrm{PCR}$ buffer with $27.5 \mathrm{mM} \mathrm{MgCl}_{2}, 5 \mu \mathrm{l}$ genomic DNA up to $500 \mathrm{ng}$ and $0.75 \mu \mathrm{l}$ DNA polymerase. For LPCR, the following program was used: a first run of 2 min at $94{ }^{\circ} \mathrm{C}$; followed by 10 cycles of $15 \mathrm{~s}$ at $95{ }^{\circ} \mathrm{C}, 30 \mathrm{~s}$ at $59{ }^{\circ} \mathrm{C}$ and $8 \mathrm{~min}$ at $72{ }^{\circ} \mathrm{C}$; followed by a second run comprising 20 cycles of $20 \mathrm{~s}$ at $95{ }^{\circ} \mathrm{C}$, $30 \mathrm{~s}$ at $61{ }^{\circ} \mathrm{C}$ and $7 \mathrm{~min}$ at $72{ }^{\circ} \mathrm{C}$ (increasing $20 \mathrm{~s}$ for each cycle), and a final extension for $7 \mathrm{~min}$ at $72{ }^{\circ} \mathrm{C}$. The primers and restriction enzymes used are shown in Table 2. RFLP-PCR was performed in a volume of $25 \mu \mathrm{l}$ containing $2.5 \mu \mathrm{l} 10 \times$ buffer specific for each enzyme, $0.6-1 \mu \mathrm{l}$ restriction enzyme and $2 \mu \mathrm{g}$ each PCR product.

The VPI gene content of the clinical isolates was analysed using 17 primer pairs with overlapping sequences (Table 2). The presence of VPI cluster genes in the environmental isolates was investigated using eight primer pairs specifically chosen to amplify within separated segments of the whole VPI cluster. The positive PCR product was then subjected to further analysis using 17 overlapping primer pairs.

Autoagglutination. For autoagglutination, all strains were grown in $\mathrm{LB}(\mathrm{pH} 6.8)$ supplemented with $1 \%(\mathrm{w} / \mathrm{v}) \mathrm{NaCl}$ and incubated at $37^{\circ} \mathrm{C}$ for $18 \mathrm{~h}$ (Chakraborty et al., 2000).
Cell culture. HT-29 and Vero cells were grown in Dulbecco's modified Eagle's medium (DMEM) supplemented with $10 \%$ fetal bovine serum (Gibco-BRL) with $100 \mathrm{U}$ penicillin $\mathrm{ml}^{-1}$ and $100 \mu \mathrm{g}$ streptomycin $\mathrm{ml}^{-1}$. The stock cultures were passaged at an interval of 2 and 4 days for Vero and HT-29 cell lines, respectively. The cultured cells were transferred to coverslips $(\varnothing=12 \mathrm{~mm}$; Corning) in the 24well-culture plates, prior to the experiment to assess adhesion of V. cholerae.

Adherence assay. Fifteen strains of $V$. cholerae belonging to different VPI PCR patterns were chosen for the adherence assay. The strains were grown in tryptic soy broth (Difco Laboratories) at $37{ }^{\circ} \mathrm{C}$ for $18 \mathrm{~h}$ with shaking. They were then harvested and washed with PBS (pH 7.4). The micro-organisms were suspended in DMEM without fetal bovine serum or antibiotics. V. cholerae ATCC 14035 was used as the positive control.

The number of vibrios to adhere to Vero and HT-29 was examined by the method of Taguchi et al. (1997). Briefly, semi-confluent cultures of Vero and HT-29 (to a final concentration of $0.5-1.5 \times 10^{6}$ cells $\mathrm{ml}^{-1}$ ) grown on plastic coverslips were placed in 24-well-culture plates. The turbidity of each bacterial suspension in DMEM was separately adjusted to $0.5 \mathrm{McFarland}$, which was confirmed by plating on nutrient agar to reach about $1 \times 10^{8}$ c.f.u. $\mathrm{ml}^{-1}$. DMEM $(1 \mathrm{ml})$ containing $V$. cholerae strains was added to each cell line and then incubated at $37{ }^{\circ} \mathrm{C}$ for $1 \mathrm{~h}$ in the presence of $5 \% \mathrm{CO}_{2}$. The coverslips were then washed three times with PBS, fixed with $70 \%$ methanol and stained with a $10 \%$ Giemsa solution. The stained coverslips were then mounted on glass slides and examined with a light microscope. A total of 100 Vero cells and 30 HT-29 cells were selected randomly

Table 1. Clinical V. cholerae strains studied, year of isolation and serogrouping

\begin{tabular}{|lccc|}
\hline \multirow{3}{*}{$\begin{array}{l}\text { Year of } \\
\text { isolation }\end{array}$} & \multicolumn{3}{c|}{ Serotype } \\
\cline { 2 - 4 } & O1-Ogawa & O1-Inaba & Non-O1-non-O139 \\
\hline 2004 & $+(9 / 9)$ & & \\
2005 & & $+(18 / 18)$ & \\
2006 & & $+(11 / 13)$ & $+(2 / 13)$ \\
Total & $9 / 40(22.5 \%)$ & $29 / 40(72.5 \%)$ & $2 / 40(5 \%)$ \\
& & & \\
\hline
\end{tabular}


Table 2. Oligonucleotide primers used in this study and restriction enzymes used for RFLP analysis

\begin{tabular}{|c|c|c|c|c|c|c|c|}
\hline \multirow{2}{*}{$\begin{array}{l}\text { Primer } \\
\text { designation }\end{array}$} & \multirow[t]{2}{*}{ Primer sequence } & \multirow[t]{2}{*}{ Reference } & \multirow{2}{*}{$\begin{array}{l}\text { PCR product } \\
\text { size (bp) }\end{array}$} & \multirow[t]{2}{*}{ Nucleotide no. } & \multirow[t]{2}{*}{ Digested by } & \multicolumn{2}{|c|}{ Applied in: } \\
\hline & & & & & & Environmental strains & Clinical strains \\
\hline LJ-F & 5'-GTGAATCTTGATGAGACGCTCTG-3' & Mukhopadhyay et al. (2001) & 1010 & 872908 & ND & + & \\
\hline LJ-R & 5- GGTGAGCCAGGCTTATTTGGG-3' & & & 873918 & & & \\
\hline LJ-F & 5'-GTGAATCTTGATGAGACGCTCTG-3' & Mukhopadhyay et al. (2001) & 2783 & 872908 & EcoRI & & + \\
\hline VPI1-R & 5'-TTGGTGGGCATCCTAACAA T-3' & This study & & 875691 & & & \\
\hline aldA-F & 5'-GCATCTGATTATGACCAAAGAATAGG-3' & Mukhopadhyay et al. (2001) & 1115 & 875605 & ND & + & \\
\hline aldA-R & 5'-GTCAATGGATGAAGCCACACAGTG-3' & & & 876720 & & & \\
\hline $\operatorname{tagA}-\mathrm{F}$ & 5'-GGTGGTAAGATATTCACTCTTAATG-3' & Sarkar et al. (2002) & 350 & 877009 & ND & + & \\
\hline tagA-R & 5'-GAGACATCTATAGAATACTGGCTG-3' & & & 877359 & & & \\
\hline aldA-F & 5'-GCATCTGATTATGACCAAAGAATAGG-3' & Mukhopadhyay et al. (2001) & 1754 & 875605 & ND & & + \\
\hline tagA-R & 5'-GAGACATCTATAGAATACTGGCTG-3' & Sarkar et al. (2002) & & 877359 & & & \\
\hline VPI2-F & 5'-TCGATGATTTAAAACCTAACAGC-3' & This study & 2605 & 877317 & DdeI & & + \\
\hline VPI2-R & 5'-ATCGAGGTAACCAGCACCAT-3' & & & 879922 & & & \\
\hline VPI3-F & 5'-CATTTTATGGTGCTGGTTACCTC-3' & This study & 2522 & 879897 & EcoRV & & + \\
\hline VPI3-R & 5'-AATGCAGCAGCATCCTTTTT 3' & & & 882419 & & & \\
\hline VPI4-F & 5'-GGGTTCGTGTAGGGAAGGAT-3' & This study & 2557 & 882393 & ClaI & & + \\
\hline VPI4-R & 5'-GCCCAGTAGGTATGCTCTGC-3' & & & 884950 & & & \\
\hline VPI5-F & 5'-TGGCTAAGCTAACTGGTGGAA-3' & This study & 2630 & 884855 & EcoRV & & + \\
\hline VPI5-R & 5'-CGCAGGCCTATAAAATTCCA-3' & & & 887485 & & & \\
\hline tcpI-F & 5'-GCCGTCTCCGCATTAAGCTCTGCAC-3' & Mukhopadhyay et al. (2001) & $\sim 5400$ & 887219 & EcoRV, BglI, ClaI & & + \\
\hline tcpQ-R & 5'-GAGGACTGTTCTGCAATCTGCTCAT-3' & & & 892604 & & & \\
\hline tcpQ-F & 5'-ATGAGCAGATTGCAGAACAGTCCTC-3' & Mukhopadhyay et al. (2001) & $\sim 7100$ & 892580 & EcoRI, EcoRV & & \\
\hline tcpF-R & 5'-GCCACGAATGTGGCTGTTATCTTATC-3' & & & 899724 & & & \\
\hline tcpA-F & 5'-CACGATAAGAAAACCGGTCAAGAG-3' & Mukhopadhyay et al. (2001) & 500 & 890480 & ND & + & \\
\hline tcpA-R & 5'-ACCAAATGCAACGCCGAATGGAGC-3' & & & 890951 & & & \\
\hline toxT-F & 5'-ACTGTATAGCAAAGCATATTCAGAGA-3' & Sarkar et al. (2002) & 1124 & 899653 & ND & + & + \\
\hline toxT-R & 5'-CAGTGATACAATCGAAAATAGGATC-3' & & & 900777 & & & \\
\hline VPI6-F & 5'-TCTGGGTTTGCTAGGCTTTC-3' & This study & 1449 & 900622 & ClaI & & + \\
\hline VPI6-R & 5'-CGGCATCAAATGGATTGTAG-3' & & & 902071 & & & \\
\hline acfB-F & 5'-TTTGTCTGAGCCGTATGTCG-3' & Sarkar et al. (2002) & 1992 & 901913 & EcoRV & + & + \\
\hline acfC-R & 5'-CACTATTTGGGGCAAAAACG-3' & & & 903905 & & & \\
\hline VPI7-F & 5'-TCATTGATAGTTTTGGAATC-3' & This study & 2655 & 903753 & EcoRV & & + \\
\hline VPI7-R & 5'-GCTTACAACCTATAAGAAAACCCAAA-3' & & & 906408 & & & \\
\hline VPI8-F & 5'-TCATTGATAGTTTTGGGTTTTCTT-3' & This study & 2717 & 906397 & EcoRI & & + \\
\hline VPI8-R & 5'-GCATTGGCTTCAGACTCTCC-3' & & & 909113 & & & \\
\hline VPI9-F & 5'-TGGTTTGTATGTACCCCGATA-3' & This study & 2121 & 909057 & EcoRV & & + \\
\hline VPI9-R & 5'-CCAACCTCAATATTAACCCTTAGGA-3' & & & 911177 & & & \\
\hline Int-F & 5'-GAAGTAATGAAACCGATAAGTGG-3' & Mukhopadhyay et al. (2001) & 311 & 913235 & ND & + & \\
\hline Int-R & 5'-TGCTTTGTACCAGTCACAGATAG-3' & & & 912924 & & & \\
\hline VPI10-F & 5'-GGGGGATCTAGTTTGCTTCC-3' & This study & 2281 & 910968 & ND & & + \\
\hline Int-R & 5'-GATAGACACTGACCATGTTTCGT-3' & & & 913248 & & & \\
\hline RJ-F & 5'-TGCTTTGTACCAGTCACAGATAG-3' & Mukhopadhyay et al. (2001) & 1475 & 912902 & $\mathrm{ND}$ & + & + \\
\hline RJ-R & 5'-TCGTTAGCGTGTCGGTTCGCAGG-3' & & & 914377 & & & \\
\hline
\end{tabular}




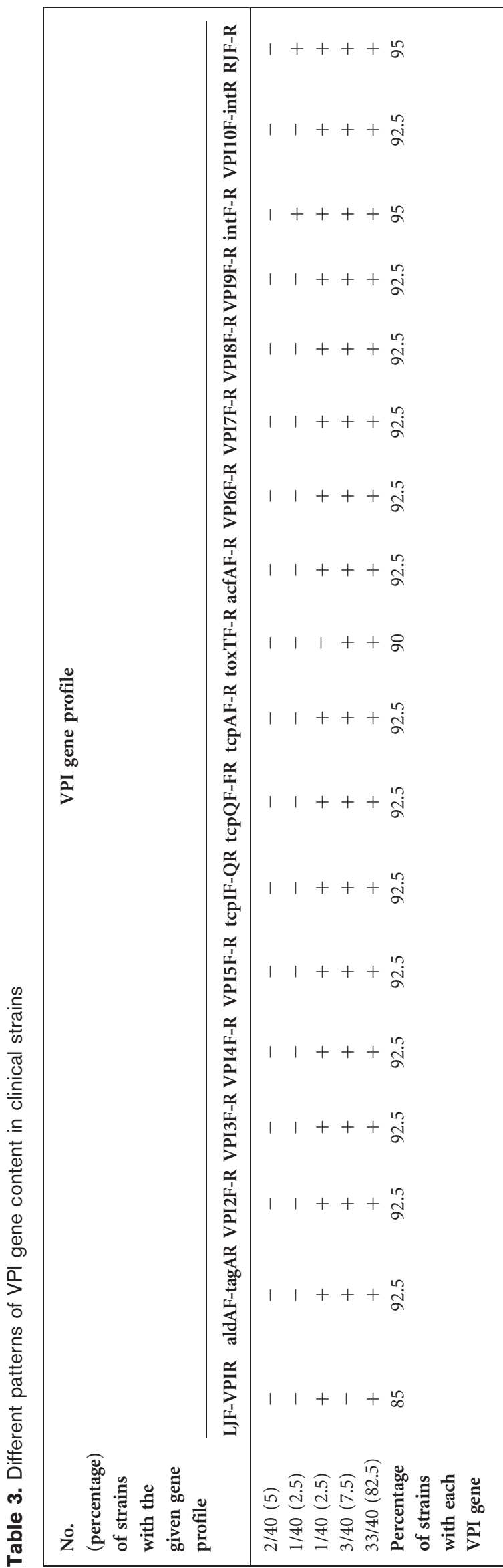

and the number of adhering micro-organisms was counted (Taguchi et al., 1997). Each experiment was performed three times.

\section{RESULTS AND DISCUSSION}

\section{Bacterial strains}

A total of $40 \mathrm{~V}$. cholerae strains were isolated from different provinces of Iran during 2004-2006. From $40 \mathrm{~V}$. cholerae isolates, 72.5 and $22.5 \%$ isolates were identified as $V$. cholerae $\mathrm{O} 1 \mathrm{El}$ Tor Inaba and Ogawa serotypes, respectively. Five per cent of the clinical and all of the environmental strains were non-O1-non-O139 (Table 1).

\section{PCR, L-PCR and RFLP analysis}

Out of 40 clinical $V$. cholerae, 33 strains $(82.5 \%)$ harboured a complete set of VPI-associated genes. Two strains (5\%) were negative for the whole VPI cluster, three $(7.5 \%)$ were negative for LJ-F/VPI1-R, one $(2.5 \%)$ was positive for int and $R J$, and one $(2.5 \%)$ was negative for toxT (Fig. 1 ). The distribution of different VPI-associated genes between the clinical and environmental $V$. cholerae isolates is presented in Tables 3 and 4, respectively.

Initially for the search of VPIs, we examined the presence of aldA-tagA, TCP and acf subclusters. An L-PCR assay of the core TCP cluster of the clinical isolates with the primers flanking tcpA (tcpI-F and tcpQ-R; tcpQ-F and tcpF-R) yielded products of the expected sizes $(\sim 5.4$ and $\sim 7.1 \mathrm{~kb})$, identical to $V$. cholerae ATCC 14035. The RFLP of L-PCR products of the clinical strains were identical and indistinguishable from V. cholerae ATCC 14035 (Fig. 2).

Three $(7.5 \%)$ clinical strains of $V$. cholerae were negative for the TCP cluster. Two and one isolates belonged to nonO1-non-O139 and O1 Inaba serotypes, respectively.

The majority of the clinical isolates ( $86 \%$ ) contained acf and aldA-tagA gene clusters. PCR analysis also showed that $36 \mathrm{~V}$. cholerae $\mathrm{O} 1$ strains $(90 \%)$ contained the toxT regulon in VPI cluster (Table 3).

The aldA-tagA, TCP and acf cluster genes were absent in $98 \%$ of the environmental strains. Only one environmentally isolated non-O1-non-O139 V. cholerae strain (EVC4) contained the entire VPI cluster of genes (lacking only tcpA and toxT). RFLP analysis of the L-PCR product of EVC4 with $t c p Q-F / t c p F-R$ primers was identical to that of $V$. cholerae ATCC 14035. The BglI endonuclease did not digest the amplified product of the $t c p I-t c p Q$ region of the EVC4 isolate. The $5.0 \mathrm{~kb}$ amplified product of $t c p I-t c p Q$ region of EVC4 was $0.4 \mathrm{~kb}$ smaller in the $t c p A$ region than the clinical and ATCC 14035 isolates, which were $5.4 \mathrm{~kb}$ in size. The smaller size of $t c p A$ could be due to the absence of the $B g l \mathrm{I}$ restriction site within the $t c p A$ of EVC4 as the result of point mutation or gene deletion (up to $400 \mathrm{bp}$ ). Amplification of the $t c p A$ gene using $t c p A-\mathrm{F} / \mathrm{T} c p A-\mathrm{R}$ primers did not yield any products, supporting the gene deletion hypothesis. 
Table 4. Different patterns of VPI gene content in environmental strains

\begin{tabular}{|c|c|c|c|c|c|c|c|c|}
\hline \multirow{2}{*}{$\begin{array}{l}\text { No. (percentage) of } \\
\text { strains with the } \\
\text { given gene profile }\end{array}$} & \multicolumn{8}{|c|}{ VPI gene profile } \\
\hline & Int & $L J$ & ald $A$ & $\operatorname{tag} A$ & tcpA El Tor & toxT & $\operatorname{acf} B-C$ & $R J$ \\
\hline $1 / 46(2.2)$ & + & + & + & + & - & - & + & + \\
\hline $2 / 46(4.3)$ & - & + & - & - & - & - & - & - \\
\hline $1 / 46(2.2)$ & + & + & - & - & - & - & - & - \\
\hline $13 / 46(28.3)$ & + & - & - & - & - & - & - & + \\
\hline $16 / 46(34.8)$ & + & - & - & - & - & - & - & - \\
\hline $13 / 46(28.3)$ & - & - & - & - & - & - & - & - \\
\hline $\begin{array}{l}\text { Percentage of } \\
\text { strains with } \\
\text { each VPI gene }\end{array}$ & 67 & 8.6 & 2 & 2 & 2 & 0 & 2 & 30 \\
\hline
\end{tabular}

EVC4 was considered as being of $t c p \mathrm{~A}^{-} / \operatorname{ctx} \mathrm{B}^{+}$genotype supporting the suggestion that not all CT positive $V$. cholera strains are TCP positive, since TCP is known to be receptor for CTX phage (Chakraborty et al., 2000). The findings reported here are supported by those of Karaolis et al. (2001) who demonstrated that the central region of the VPI of $t c p \mathrm{~A}$ contains most of the divergence between the VPIs of the 6th (classic) and the 7th (El Tor) pandemic strains. Previous

(a)

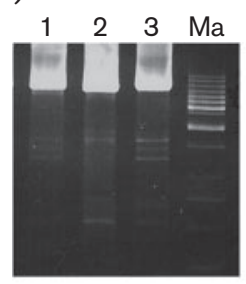

(b)

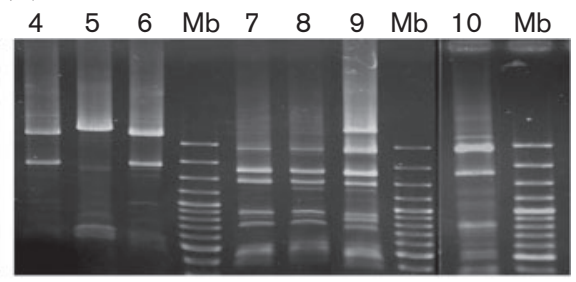

(c)

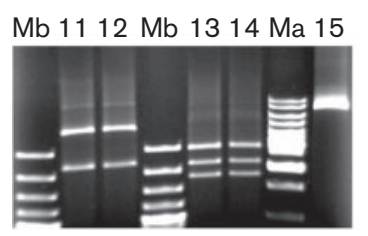

Fig. 2. (a) L-PCR amplification of $t c p /-F / t c p Q-R$ in the TCP cluster. Lanes: 1, representative of clinical $V$. cholerae strains; 2, EVC4; 3, V. cholerae ATCC 14035. (b) RFLP pattern of amplified products using tcpl-F/tcpQ-R primers. Lanes: 4, 5 and 6, representatives of $B g /$ digests of clinical $V$. cholerae strains, EVC4 and V. cholerae ATCC 14035, respectively; 7, 8, 9 and 10, representatives of EcoRV digests of two clinical $V$. cholerae strains, V. cholerae ATCC 14035 and EVC4, respectively. (c) L-PCR amplification of tcpQ-F/tcpF-R in TCP cluster. Lanes: 11 and 12, EcoRV digests of EVC4 and clinical V. cholerae strains (identical to ATCC 14035), respectively; 13 and 14, EcoRI digests of EVC4 and clinical $V$. cholerae strains (identical to ATCC 14035), respectively; lane 15, L-PCR product of tcpQ-F/tcpF-R in V. cholerae ATCC 14035. Ma, 1 kb DNA size marker; Mb, 100 bp DNA size marker. studies by others have described that the genetic variants of the TCP island were carried by a number of environmental $V$. cholerae strains belonging to non-epidemic serogroups (Boyd \& Waldor, 2002; Mukhopadhyay et al., 2001; Tay et al., 2008). Overall, the consensus all published reports have indicates mutational events in the $t c p$ region. To the best of our knowledge this is the first report suggesting deletion in the $t c p A$ region.

Among the environmental strains, six different patterns of the VPI gene cluster were obtained, among which $30,8.6$ and $67 \%$ of isolates contained the $R J, L J$ and int gene, respectively. The implication from these results may be that: (i) some environmental strains could have acquired VPI phage; however, due to phages' size limitation they did not acquire the whole phage genomics; and (ii) the ability of $V$. cholerae to acquire, integrate and excise the VPI cluster is mediated by the VPI-encoded recombinase int and vpiT (Karaolis et al., 1998; Rajanna et al., 2003). Generation of amplicons with right and left junction primers suggests that VPIs have been integrated in the large chromosome of these isolates at sites identical to those of O1 strains (Fasano et al., 1991). Murphy \& Boyd (2008) showed that all three pathogenicity islands can excise from the chromosome, which is likely a first step in their horizontal transfer. Boyd et al. (2000) suggest that Vibrio mimicus may be a significant reservoir for VPI phage and may play an important role in the emergence of new toxigenic $V$. cholerae isolates.

\section{Autoagglutination and adherence assay}

To determine the $t c p A$ gene expression, all of the TCP cluster positive strains ( $n=37$ ) were examined for autoagglutination. It was found that $36(97 \%)$ of the clinical strains exhibited the autoagglutination phenotype. Autoagglutination was not observed in any other broth medium or culture condition in the remaining clinical strains (3\%) and the single environmental strain tested.

The adherence assay on Vero and HT-29 cells was carried out for five environmental and ten clinical $V$. cholerae strains including V. cholerae ATCC 14035 (Fig. 3). Similar 
(a)

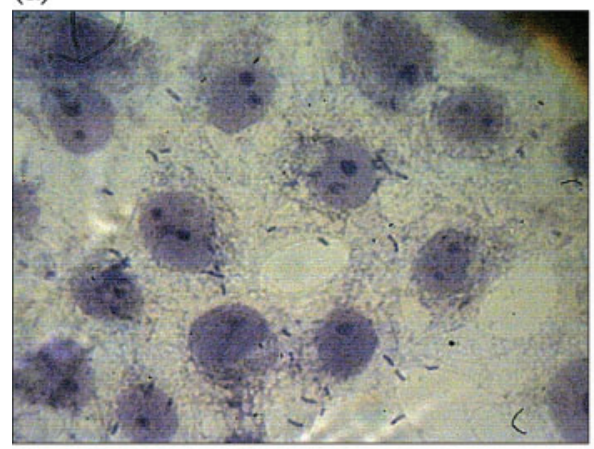

(c)

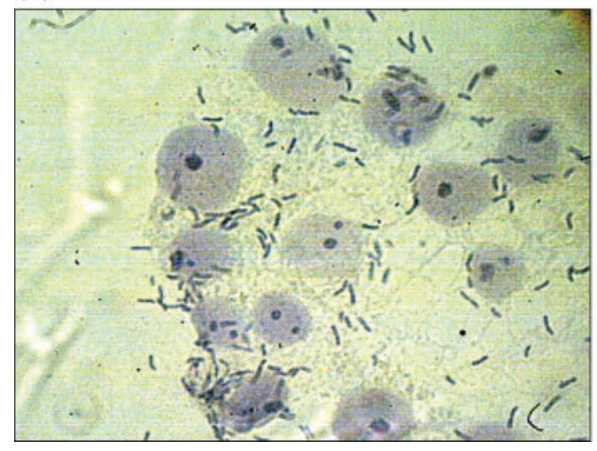

(b)

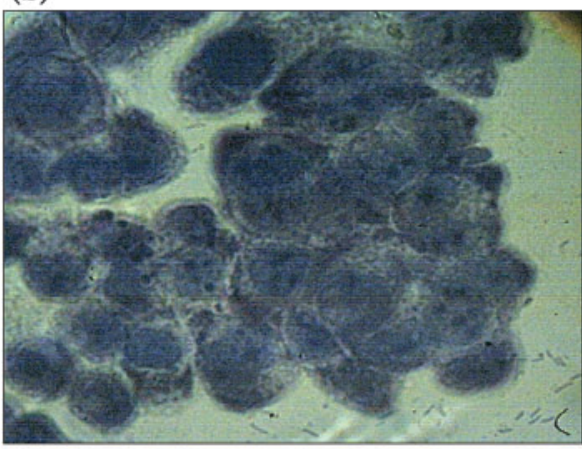

(d)

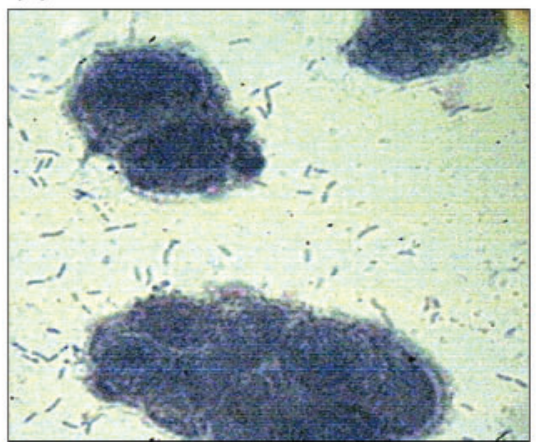

Fig. 3. Giemsa-stained bright-field micrographs of Vero and HT-29 cells inoculated with $V$. cholerae strains. Adherence of bacteria with weak attachment pattern on Vero (a) and HT-29 (b) cells. Adherence of bacteria with strong attachment pattern on Vero (c) and HT-29 (d) cells.

adherence results (dispersed or diffused) were obtained when $V$. cholerae isolates were incubated with either HT-29 or Vero cell lines. Amongst the V. cholerae strains, CVC1 and
EVC4 showed the strongest adhesion (about 16 bacteria per cell). However, the CVC8 and EVC3 strains exhibited the weakest adhesion (about 7 bacteria per cell) (Table 5).

Table 5. Adherence of $V$. cholerae strains to Vero and HT-29 cells assessed by light microscopy

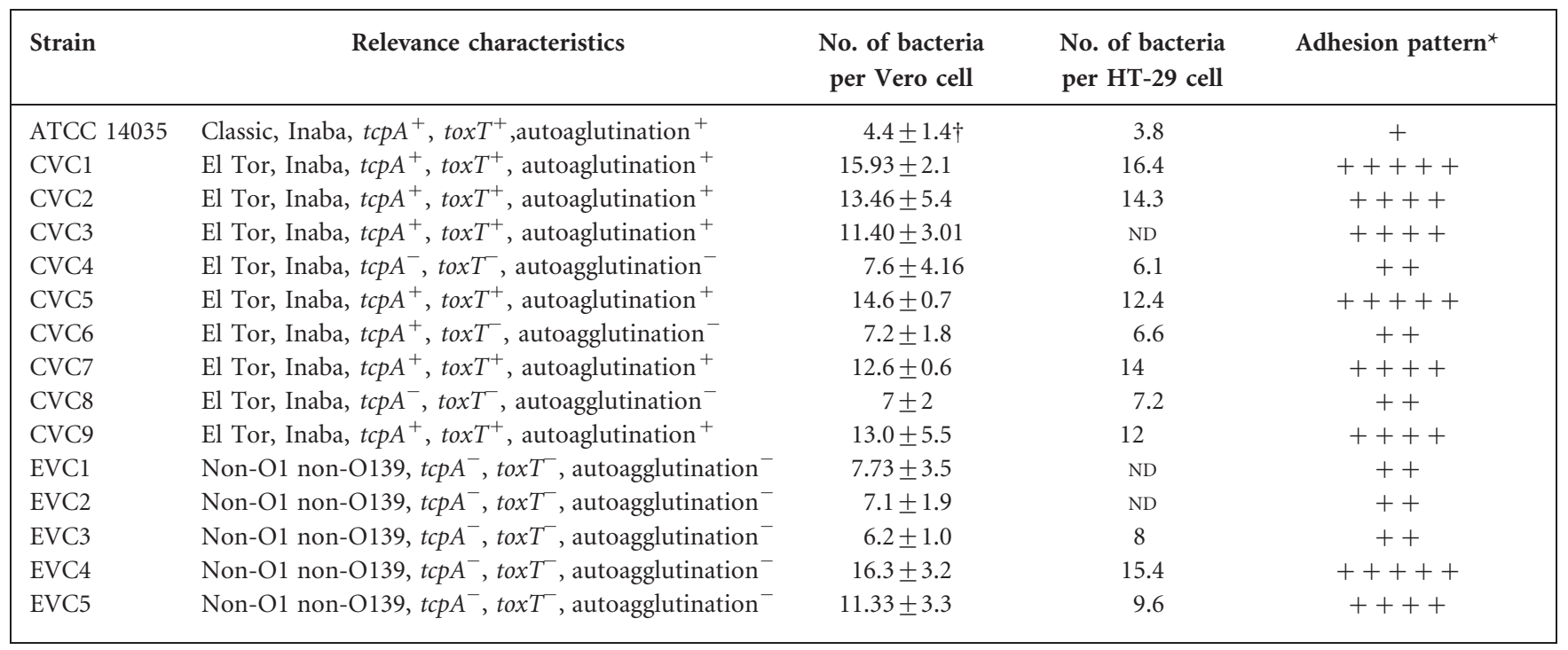

CVC, Clinical Vibrio cholera; EVC, environmental V. cholerae; ND, not done.

${ }^{*}$ Strong adhesion, $\geqslant+++$; weak adhesion, $\leqslant+++$.

$\dagger$ Values were recorded as mean \pm SEM each in triplicate. 
Amongst the total clinical strains, four (10\%) did not contain toxT, and one of which contained all other VPIassociated genes. The strain, CVC6, showed no autoagglutination but a weak attachment on HT-29 and Vero cells. Two other tox $\mathrm{T}^{-}$strains (CVC4 and CVC8) did not contain any genes of the VPI cluster nor show an autoagglutination phenotype. They presented, however, a weak attachment on Vero and HT-29 cell lines. $t c p A^{+} /$tox $^{+}$strains showed a typical autoagglutination and strong attachment to the cells. Chakraborty et al. (2000) studied environmental strains of $V$. cholerae and demonstrated that strains carrying both tcpA and toxT showed an autoagglutination phenotype, whereas strains positive for tcpA but negative for toxT did not autoagglutinate. However, they did not associate the autoagglutination with the cellular adhesion. Based on the results presented in our study we propose the hypothesis that the strong bacteria/ cell attachment is a multi-factorial phenotype due to the presence of different colonization factors including TcpA. Weak attachment to cells was seen in strains with no Tcp expression and autoagglutination (either tcp $A^{-}$toxT $T^{-}$or $\operatorname{tcp} A^{+}$toxT $)$, possibly due to colonization factors other than Tcp or to non-specific attachment mediated by the bacterial cell surface.

In this study, V. cholerae ATCC 14035 (the positive control) showed a weak attachment to Vero and HT-29 cells (characteristic of weak virulent strains), which is consistent with the study done by Pruzzo et al. (2003), revealing the possibility of development of atypical or mild clinical forms of cholera. Data presented by others (Baselski et al., 1978; Smirnova et al., 2004) also support this hypothesis.

In the environmental strains, the cellular attachment followed a different pattern than that observed in the clinical isolates. Two of our environmental strains (EVC4 and EVC5) with tcpA $A^{-} /$tox $T^{-}$genotype showed strong adhesive properties to the cells. Non-fimbrial adhesive factors such as MSHA (mannose sensitive haemagglutinin antigen) and $53 \mathrm{kDa}$ CBP (chitin binding protein) have been suggested as colonization factor candidates (Kirn et al., 2005; Zampini et al., 2005; Vezzulli et al., 2008). Other colonization factors such as TcpF, TcpI and AcfB have recently been identified (Kirn et al., 2003; Chaparro et al., 2010). Other unknown colonization factors may also play role in the $\mathrm{TCP}^{-}$non-O1-non-O139 environmental $V$. cholerae strains as suggested by Faruque et al. (2004).

In conclusion, this study shows that the strong attachment of the clinical isolates of $V$. cholerae to the cell lines could be due to the intact structure of the pathogenicity island. However, the mosaic structure of the VPI in the environmental strains might be attributed to selective pressure of the environmental signals that render them to express and use adhesive molecules other than TCP.

\section{ACKNOWLEDGEMENTS}

The study was funded by Pasteur Institute of Iran grant numbers 170 and 312 . We are very grateful to the Tehran Water and Sewage
Company, with special thanks to Mrs Parvar and Mrs Motallebi for kindly providing surface water samples.

\section{REFERENCES}

Bakhshi, B., Pourshafie, M. R., Navabakbar, F. \& Tavakoli, A. (2008). Genomic organisation of the CTX element among toxigenic Vibrio cholerae isolates. Clin Microbiol Infect 14, 562-568.

Bakhshi, B., Barzelighi, H. M., Adabi, M., Lari, A. R. \& Pourshafie, M. R. (2009). A molecular survey on virulence associated genotypes of non-O1 non-O139 Vibrio cholerae in aquatic environment of Tehran, Iran. Water Res 43, 1441-1447.

Baselski, V. S., Upchurch, S. \& Parker, C. D. (1978). Isolation and phenotypic characterization of virulence-deficient mutants of Vibrio cholerae. Infect Immun 22, 181-188.

Boyd, E. F. \& Waldor, M. K. (2002). Evolutionary and functional analyses of variants of the toxin-coregulated pilus protein TcpA from toxigenic Vibrio cholerae non-O1/non-O139 serogroup isolates. Microbiology 148, 1655-1666.

Boyd, E. F., Moyer, K. E., Shi, L. \& Waldor, M. K. (2000). Infectious CTXPhi and the vibrio pathogenicity island prophage in Vibrio mimicus: evidence for recent horizontal transfer between $V$. mimicus and V. cholerae. Infect Immun 68, 1507-1513.

Carroll, P. A., Tashima, K. T., Rogers, M. B., DiRita, V. J. \& Calderwood, S. B. (1997). Phase variation in $t c p H$ modulates expression of the ToxR regulon in Vibrio cholerae. Mol Microbiol 25, 1099-1111.

Chakraborty, S., Mukhopadhyay, A. K., Bhadra, R. K., Ghosh, A. N., Mitra, R., Shimada, T., Yamasaki, S., Faruque, S. M., Takeda, Y. \& other authors (2000). Virulence genes in environmental strains of Vibrio cholerae. Appl Environ Microbiol 66, 4022-4028.

Chaparro, A. P., Ali, S. K. \& Klose, K. E. (2010). The ToxT-dependent methyl-accepting chemoreceptors AcfB and TcpI contribute to Vibrio cholerae intestinal colonization. FEMS Microbiol Lett 302, 99-105.

Choopun, N., Louis, V., Huq, A. \& Colwell, R. R. (2002). Simple procedure for rapid identification of Vibrio cholerae from the aquatic environment. Appl Environ Microbiol 68, 995-998.

DiRita, V. J., Parsot, C., Jander, G. \& Mekalanos, J. J. (1991). Regulatory cascade controls virulence in Vibrio cholerae. Proc Natl Acad Sci U S A 88, 5403-5407.

Faruque, S. M., Chowdhury, N., Kamruzzaman, M., Dziejman, M., Rahman, M. H., Sack, D. A., Nair, G. B. \& Mekalanos, J. J. (2004). Genetic diversity and virulence potential of environmental Vibrio cholerae population in a cholera-endemic area. Proc Natl Acad Sci U S A 101, 2123-2128.

Fasano, A., Baudry, B., Pumplin, D. W., Wasserman, S. S., Tall, B. D., Ketley, J. M. \& Kaper, J. B. (1991). Vibrio cholerae produces a second enterotoxin, which affects intestinal tight junctions. Proc Natl Acad Sci U S A 88, 5242-5246.

Häse, C. C. \& Mekalanos, J. J. (1998). TcpP protein is a positive regulator of virulence gene expression in Vibrio cholerae. Proc Natl Acad Sci U S A 95, 730-734.

Heidelberg, J. F., Eisen, J. A., Nelson, W. C., Clayton, R. A., Gwinn, M. L., Dodson, R. J., Haft, D. H., Hickey, E. K., Peterson, J. D. \& other authors (2000). DNA sequence of both chromosomes of the cholera pathogen Vibrio cholerae. Nature 406, 477-483.

Hughes, K. J., Everiss, K. D., Kovach, M. E. \& Peterson, K. M. (1995). Isolation and characterization of the Vibrio cholerae acfA gene, required for efficient intestinal colonization. Gene 156, 59-61.

Karaolis, D. K., Johnson, J. A., Bailey, C. C., Boedeker, E. C., Kaper, J. B. \& Reeves, P. R. (1998). A Vibrio cholerae pathogenicity island 
associated with epidemic and pandemic strains. Proc Natl Acad Sci U S A 95, 3134-3139.

Karaolis, D. K., Lan, R., Kaper, J. B. \& Reeves, P. R. (2001), Comparison of Vibrio cholerae pathogenicity islands in sixth and seventh pandemic strains. Infect Immun 69, 1947-1952.

Kirn, T. J., Lafferty, M. J., Sandoe, C. M. \& Taylor, R. K. (2000). Delineation of pilin domains required for bacterial association into microcolonies and intestinal colonization by Vibrio cholerae. Mol Microbiol 35, 896-910.

Kirn, T. J., Bose, N. \& Taylor, R. K. (2003). Secretion of a soluble colonization factor by the TCP type 4 pilus biogenesis pathway in Vibrio cholerae. Mol Microbiol 49, 81-92.

Kirn, T. J., Jude, B. A. \& Taylor, R. K. (2005). A colonization factor links Vibrio cholerae environmental survival and human infection. Nature 438, 863-866.

Mukhopadhyay, A. K., Chakraborty, S., Takeda, Y., Nair, G. B. \& Berg, D. E. (2001). Characterization of VPI pathogenicity island and CTXphi prophage in environmental strains of Vibrio cholerae. J Bacteriol 183, 4737-4746.

Murphy, R. A. \& Boyd, E. F. (2008). Three pathogenicity islands of Vibrio cholerae can excise from the chromosome and form circular intermediates. J Bacteriol 190, 636-647.

Nandi, B., Nandy, R. K., Mukhopadhyay, S., Nair, G. B., Shimada, T. \& Ghose, A. C. (2000). Rapid method for species-specific identification of Vibrio cholerae using primers targeted to the gene of outer membrane protein OmpW. J Clin Microbiol 38, 4145-4151.

Parsot, C. \& Mekalanos, J. J. (1991). Expression of the Vibrio cholerae gene encoding aldehyde dehydrogenase is under control of ToxR, the cholera toxin transcriptional activator. J Bacteriol 173, 2842-2851.

Peterson, K. M. \& Mekalanos, J. J. (1988). Characterization of the Vibrio cholerae ToxR regulon: identification of novel genes involved in intestinal colonization. Infect Immun 56, 2822-2829.

Pruzzo, C., Tarsi, R., Del Mar Lleò, M., Signoretto, C., Zampini, M., Pane, L., Colwell, R. R. \& Canepari, P. (2003). Persistence of adhesive properties in Vibrio cholerae after long-term exposure to sea water. Environ Microbiol 5, 850-858.

Rajanna, C., Wang, J., Zhang, D., Xu, Z., Ali, A., Hou, Y. M. \& Karaolis, D. K. (2003). The vibrio pathogenicity island of epidemic Vibrio cholerae forms precise extrachromosomal circular excision products. J Bacteriol 185, 6893-6901.

Restrepo, D., Huprikar, S. S., VanHorn, K. \& Bottone, E. J. (2006). O1 and non-O1 Vibrio cholerae bacteremia produced by hemolytic strains. Diagn Microbiol Infect Dis 54, 145-148.

Rozemeijer, W., Korswagen, L. A., Voskuyl, A. E. \& Budding, A. E. (2009). Vibrio cholerae non-O1 non-O139 infection in an immunocompromised patient returning from Spain, July 2009. Euro Surveill 14, 19298.

Sarkar, A., Nandy, R. K., Nair, G. B. \& Ghose, A. C. (2002). Vibrio pathogenicity island and cholera toxin genetic element-associated virulence genes and their expression in non-O1 non-O139 strains of Vibrio cholerae. Infect Immun 70, 4735-4742.

Smirnova, N. I., Cheldyshova, N. B., Zadnova, S. P. \& Kutyrev, V. V. (2004). Molecular-genetic peculiarities of classical biotype Vibrio cholerae, the etiological agent of the last outbreak Asiatic cholera in Russia. Microb Pathog 36, 131-139.

Szabady, R. L., Yanta, J. H., Halladin, D. K., Schofield, M. J. \& Welch, R. A. (2011). TagA is a secreted protease of Vibrio cholerae that specifically cleaves mucin glycoproteins. Microbiology 157, 516-525.

Taguchi, H., Yamaguchi, H., Osaki, T. Y., Yamamoto, T., Ogata, S. \& Kamiya, S. (1997). Flow cytometric analysis for adhesion of Vibrio cholerae to human intestinal epithelial cell. Eur J Epidemiol 13, 719724.

Tay, C. Y., Reeves, P. R. \& Lan, R. (2008). Importation of the major pilin TcpA gene and frequent recombination drive the divergence of the vibrio pathogenicity island in Vibrio cholerae. FEMS Microbiol Lett 289, 210-218.

Taylor, R., Shaw, C., Peterson, K., Spears, P. \& Mekalanos, J. (1988). Safe, live Vibrio cholerae vaccines? Vaccine 6, 151-154.

Vezzulli, L., Pezzati, E., Repetto, B., Stauder, M., Giusto, G. \& Pruzzo, C. (2008). A general role for surface membrane proteins in attachment to chitin particles and copepods of environmental and clinical vibrios. Lett Appl Microbiol 46, 119-125.

Zampini, M., Pruzzo, C., Bondre, V. P., Tarsi, R., Cosmo, M., Bacciaglia, A., Chhabra, A., Srivastava, R. \& Srivastava, B. S. (2005). Vibrio cholerae persistence in aquatic environments and colonization of intestinal cells: involvement of a common adhesion mechanism. FEMS Microbiol Lett 244, 267-273. 